\title{
Diagnóstico das atividades de educação ambiental em unidades de conservação: propondo ações no contexto atual
}

Diagnosis of environmental education activities in conservation units: proposed actions in the current context

\author{
Fabrícia Barbieri', Paulo Romeu Machado", Denis Rasquin Rabenschlag"', \\ Ísis Samara Ruschel Pasquali ${ }^{i v}$
}

\begin{abstract}
RESUMO
O presente trabalho apresenta um diagnóstico das atividades de educação ambiental em Unidades de Conservação, faz um levantamento dos problemas enfrentados pelas UCs e propõe ações para auxiliar na efetividade destas atividades. O estudo foi realizado através de um questionário onde seis UCs responderam à pesquisa: Parque Nacional Aparados da Serra e Parque Nacional da Serra Geral, Parque Estadual Delta do Jacuí e Área de Proteção Ambiental Estadual Delta do Jacuí, Parque Estadual de Itapeva, Parque Estadual de Itapuã, Área de Proteção Ambiental do Banhado Grande e Parque Natural Municipal Morro do Osso. Todas as UCs informaram realizar alguma atividade de educação ambiental, com exceção da APA Banhado Grande. O principal problema citado para a não realização das atividades é a falta de incentivo financeiro e falta de pessoal. Sobre as necessidades para a efetividade das ações e alcance dos objetivos da UC, foram citadas: a falta de recursos humanos, capacitação de pessoal, recursos financeiros e fiscalização. Ações propostas pelo estudo para auxiliar a gestão e tornar ações efetivas, incluem: diagnóstico rápido participativo, pesquisas de educação ambiental em UC, parcerias com outras instituições, capacitação de educadores ambientais, estratégias de arrecadação de recursos financeiros, monitoramento e acompanhamento da efetividade das atividades.
\end{abstract}

Palavras-chave: Educação Ambiental; Unidades de Conservação; Conflitos; Gestão Ambiental

\section{ABSTRACT}

The present work presents a diagnosis of the activities of environmental education in Conservation Units, makes a survey of the problems faced and proposes actions to assist in the effectiveness of these activities. The study was conducted through a questionnaire where six UCs answered the survey: Parque Nacional Aparados da Serra and Parque Nacional da Serra Geral, Parque Estadual Delta do Jacuí and Área de Proteção Ambiental Estadual Delta do Jacuí, Parque Estadual de Itapeva, Parque Estadual de Itapuã, Área de Proteção Ambiental do Banhado Grande and Parque Natural Municipal Morro do Osso. All the CUs reported to carry out some environmental education activities, except for the APA Banhado Grande. The main problem cited for not doing the actions is the lack of financial incentive and lack of personnel. Regarding the needs for the effectiveness of the actions and achievement of the objectives of the $\mathrm{CU}$, were cited: lack of human resources, training of personnel and financial resources and inspection. Actions proposed to assist management and make effective actions include: participatory rapid diagnosis, environmental education research in CU, partnerships with other institutions, training of environmental educators, other strategies for raising financial resources and monitoring the effectiveness of activities.

Keywords: Environmental education; Conservation units; Conflicts; Environmental management

\section{INTRODUÇÃO}

Segundo Gross, et al. (2006, p. 8), o Brasil possui de 15 a 20\% da biodiversidade mundial, e é considerado o país mais megadiverso do mundo. Apesar de ter contribuído significativamente para a expansão de áreas protegidas desde 2003, conforme relata o Ministério do Meio Ambiente (2010), o Brasil teve uma crescente expansão da economia, levando ao aumento da demanda por terras produtivas e infraestruturas, o que levou ao aumento da degradação ambiental em diversas áreas (MINISTÉRIO DO MEIO AMBIENTE, 2010).

'Especialista em Educação Ambiental, Centro de Tecnologia, Universidade Federal de Santa Maria, Santa Maria, RS, Brasil. fabribarbieris@gmail.com II, III, vProfessor, Centro de Tecnologia, Universidade Federal de Santa Maria, Santa Maria, RS, Brasil. isis.ambiental@hotmail.com; promeu.machado@ gmail.com; denis.rabenschlag@gmail.com 
Isso contribuiu para que diversas espécies fossem listadas como ameaçadas de extinção, sobre-exploradas economicamente, ecossistemas degradados e recursos genéticos em processo de desaparecimento (GROSS et al., 2006).

Segundo Hassler (2005), a criação das unidades de conservação significou um grande avanço no que diz respeito à preservaçáo e conservaçáo dos recursos naturais, uma vez que, pelo menos em parte, diminuiu o processo de desmatamento de áreas naturais. Neste contexto, é inquestionável a importância das unidades de conservaçáo e áreas protegidas para a conservação do meio ambiente, sobre diversos aspectos, desde ambientais, ecológicos a socioambientais. Importante acrescentar que, o Brasil possui mais de 8\% do território formado por unidades de conservação e $12 \%$ por terras indígenas, além disso, possui grandes Áreas de Preservaçáo Permanente e Reservas Legais, formando uma rede importante de áreas protegidas (GROSS et al., 2006, p. 8).

No entanto, a criação de unidades de conservação, por si só, não garante a efetividade de conservação ou preservação pretendida. Um conjunto de outros fatores influencia no sucesso na implementação de uma UC, como aplicação da legislação e manejo sustentável de recursos naturais no seu entorno (HESSLER, 2005). Para o WWF (2012), diversos aspectos - técnicos, políticos e econômicos - são essenciais para que os objetivos da criação de uma UC sejam alcançados, como: planejamento, área, localização e conectividade com outras áreas naturais, programas de desenvolvimento regional, fiscalização, capacidade institucional, aspectos legais, e etc....

Muitos problemas e conflitos ocorrem em unidades de conservação, uma vez que há muitas dificuldades em conciliar o desenvolvimento econômico e a preservação ambiental. Podem-se citar alguns estudos que identificaram estes problemas, como: falta de recursos financeiros e humanos para adequada gestáo em unidades de conservação, falta de fiscalização ambiental, dificuldades e conflitos com comunidades locais, baixa participação popular na criação e gestão de áreas protegidas, envolvimento da sociedade como um todo na conservação e preservação ambiental (BROCKELMAN e GRIFFITHS, 2002; GROSS et al., 2006; LIMA, et al., 2005; MINISTÉRIO DO MEIO AMBIENTE, 2010).

O fácil acesso às áreas, o valor do mercado, a demanda por recursos, as dificuldades de controle de atividades ilegais são os fatores que deixam as unidades de conservação mais vulneráveis (WWF, 2012). Para Brockelman e Griffiths (2002), um dos grandes problemas para alcançar os objetivos propostos para a criação das unidades de conservação é a deficiência na fiscalização. A situação é preocupante uma vez que, o planejamento adequado e a disponibilidade de recursos sáo essenciais para que os objetivos da UC sejam alcançados (WWF, 2012).

A Educação Ambiental pode ser uma importante aliada para que as unidades de conservação cumpram o seu papel e atinjam com sucesso os objetivos de sua criação. Nestas áreas, atividades de Educação Ambiental possuem o intuito de trazer mudanças no comportamento das pessoas em relação ao meio ambiente, auxiliando para a construçáo de novos conhecimentos e valores, imprescindíveis para a conservação e o desenvolvimento socioambiental (MINISTÉRIO DO MEIO AMBIENTE, 2016).

Comunidades locais que vivem no entorno ou dentro de unidades de conservação, como povos indígenas, os quilombolas, os caiçaras, os seringueiros, na maioria das vezes, não participam de forma significativa na tomada de decisóes nacionais e internacionais sobre a biodiversidade, o que pode afetar seriamente sua cultura e modos de vida (GROSS et al., 2006). Lima, et al. (2005) cita alguns problemas que podem gerar conflitos entre comunidades locais e unidades de conservação, são eles: expectativas não atendidas, desapropriação sem indenização, lucro e produção cessante, desestabilização cultural, déficit tributário pela redução de produção e paralisação do processo de desenvolvimento regional. Todos estes problemas podem gerar insatisfação por parte das comunidades locais, assim como, uma relação conflituosa com a unidade de conservação, e consequentemente, problemas de conservação dos recursos naturais existentes.

Conforme afirma Quintas (2006), a relaçáo cotidiana e individual do sujeito com o meio ambiente e os recursos naturais pode ser modificada através da Educação Ambiental, promovendo a formação de comportamentos ambientalmente responsáveis no meio social. Ao mesmo tempo, este mesmo autor considera que, a Educação Ambiental também deve estar direcionada para as causas estruturais dos problemas ambientais, onde haja uma leitura destes problemas sob o aspecto da complexidade do meio social. Nesta percepção, a Educação Ambiental deve trazer uma postura dialógica, problematizadora e comprometida com as transformaçôes estruturais do meio social, com a participaçáo do sujeito no processo coletivo de transformação, e a partir disso, surgindo a transformação individual de cada pessoa (QUINTAS, 2006).

Para tanto, a Educação Ambiental, com o objetivo de envolvimento e engajamento das comunidades locais que vivem em unidades de conservação e em seu entorno, é uma estratégia imprescindível para conservação dos recursos naturais, históricos e culturais destas áreas (MINISTÉRIO DO MEIO AMBIENTE, 
2016). Para Loureiro e Cunha (2008, p. 239) a educação ambiental também é fundamental para o processo de gestão participativa em UC's, incluindo como pressuposto para a formação do conselho de UC, promovendo "um espaço/processo educativo participativo e emancipatório".

Neste contexto, este estudo possui o objetivo de trazer informaçôes sobre a realização de atividades de Educação Ambiental em UCs, assim como informaçóes acerca das dificuldades encontradas na gestão destas UCs, para a realização e efetivação destas atividades. Assim como, objetiva propor açóes que possam contribuir com a realização efetiva de atividades de Educação Ambiental.

\section{METODOLOGIA}

\section{I Área de Estudo: Unidades de Conservação}

Foram selecionadas Unidades de Conservação (UC) localizadas no Estado do Rio Grande do Sul, sendo duas geridas pela esfera Municipal, cinco pela esfera Estadual e duas pela esfera Federal e de diferentes categorias de proteção integral e de uso sustentável. Entretanto, das nove UCs convidadas a participarem, apenas seis responderam à pesquisa, enviando os questionários preenchidos, são elas: Parque Nacional Aparados da Serra e Parque Nacional da Serra Geral (mesma gestáo), Parque Estadual Delta do Jacuí e Área de Proteção Ambiental Estadual Delta do Jacuí (mesma gestão), Parque Estadual de Itapeva, Parque Estadual de Itapuã, Área de Proteção Ambiental (APA) do Banhado Grande e Parque Natural Municipal Morro do Osso.

Através de consulta aos sites dos órgãos gestores das respectivas UCs (ICMBio, SEMA e SMAM/ POA), foram compiladas algumas informações sobre estas unidades, as quais estão apresentadas abaixo:

a) Parque Nacional (PARNA) Aparados da Serra e Parque Nacional (PARNA) da Serra Geral

O PARNA Aparados da Serra e o PARNA da Serra Geral são UCs da categoria de proteção integral e são geridas pelo Instituto Chico Mendes de Conservação da Biodiversidade (ICMBio). Estão localizadas entre os municípios de Cambará do Sul (RS), Praia Grande e Jacinto Machado (SC) possuindo um território total de 27.000 ha em área do Bioma Mata Atlântica. Atualmente estas UCs possuem um Plano de Manejo, o qual abrange as duas áreas, assim como, a gestão dos parques é de responsabilidade de uma equipe única.

b) Parque Estadual (PE) Delta do Jacui e Área de Proteção Ambiental (APA) Estadual Delta do Jacuí

O PE do Delta do Jacuí e a APA Delta do Jacuí são UCs da categoria de proteção integral e categoria de uso sustentável, respectivamente, e são geridas pela Secretaria do Ambiente e Desenvolvimento Sustentável (SEMA). Estấo localizadas entre os municípios de Porto Alegre, Canoas, Eldorado do Sul, Nova Santa Rita, Triunfo e Charqueadas em área dos Biomas Mata Atlântica e Pampa. O PE do Delta do Jacuí apresenta 12.242ha, e a APA compartilha $62 \%$ de sua área total (22.826ha) com o Parque. Apenas o PE do Delta do Jacuí apresenta plano de manejo e zona de amortecimento e a gestão destas UCs é de responsabilidade de uma equipe única.

c) Parque Estadual (PE) de Itapeva

O PE de Itapeva é uma UC da categoria de proteção integral e é gerida pela Secretaria do Ambiente e Desenvolvimento Sustentável (SEMA). Está localizado no município de Torres, possuindo 1.000 ha, em área do Bioma Mata Atlântica. O PE possui plano de manejo e a zona de amortecimento, conforme estabelecido no plano, leva em consideração atributos ambientais importantes a serem conservados.

d) Parque Estadual (PE) de Itapuã

O PE de Itapuã é uma UC da categoria de proteção integral e é gerida pela Secretaria do Ambiente e Desenvolvimento Sustentável (SEMA). Está localizado no município de Viamão e possui atualmente uma área de 5.566,50 ha em área do Bioma Pampa. A área é um dos últimos remanescentes originais da região metropolitana de Porto Alegre. Esta UC possui plano de manejo.

e) Area de Proteção Ambiental (APA) do Banhado Grande

A APA do Banhado Grande é uma UC da categoria de uso sustentável e é gerida pela Secretaria do Ambiente e Desenvolvimento Sustentável (SEMA). Está localizada entre os municípios de Glorinha, Gravataí, Santo Antônio da Patrulha e Viamão e possui 136.935 ha em áreas dos Biomas Mata Atlântica e Pampa. O plano de manejo desta UC está em elaboração

f) Parque Natural Municipal (PNM) Morro do Osso

O PNM Morro do Osso é uma UC da categoria de proteção integral e é gerida pela Prefeitura Municipal de Porto Alegre. Está localizado no município de Porto Alegre e, atualmente, o parque abrange uma área de 127 ha em área do Bioma Pampa. Constitui-se num importante reduto biológico, praticamente isolado 
pela urbanização dos bairros urbanizados do entorno do Morro do Osso. Esta UC possui plano de manejo.

\subsection{Pesquisa Quali-Quantitativa}

Para a realização do diagnóstico das atividades de educação ambiental, assim como o levantamento das dificuldades enfrentadas pela gestão das UCs estudadas, foi realizada uma pesquisa através de um questionário com os gestores e técnicos que trabalham nestas UCs.

Esta pesquisa foi guiada por um questionário, contendo questóes abertas (onde o entrevistado comenta o assunto) e questóes fechadas semi-estruturadas (respostas do tipo sim ou não, ou respostas curtas já com alternativas estabelecidas). Este tipo de pesquisa segue um esquema pré-estabelecido, mas não rígido, exibindo certa maleabilidade permitindo que o pesquisador faça as adaptaçôes necessárias (ZAPPES, 2007).

Num primeiro momento, foi realizado um contato telefônico com o intuito de apresentação do trabalho. Inicialmente houve a tentativa de contato diretamente com o gestor das unidades de conservaçáo, quando isto não foi possível, houve então contato com técnicos que trabalham na UC, e em alguns casos, houve contato com o responsável pela realização das atividades de educação ambiental. Posteriormente a este contato inicial, houve o envio do questionário, em formato Word, via e-mail para a pessoa contatada. Nem todos os contatos e questionários enviados foram respondidos, ou seja, não houve retorno de algumas UCs contatadas. De qualquer forma, esta informação foi adicionada nos resultados do trabalho. Foram realizadas análises qualitativas e quantitativas, quando possível, das questóes.

\subsection{PROPOSIÇÃo de AÇÕES}

Ao final do trabalho, após análise dos resultados obtidos com os questionários, foram propostas açôes que possam auxiliar de alguma forma a gestão das UCs a realizarem atividades de EA com as populaçôes locais. Para proposição destas açóes, foi realizada uma pesquisa em busca de casos em que atividades de EA são ou foram realizadas com êxito, assim como, se realizou a busca por publicaçóes, como cartilhas, livros ou outro material similar, principalmente em sites do governo (ex. MMA, ICMBio, SEMA/RS), com o intuito de compilar informaçóes e/ou dicas que pudessem auxiliar a gestão das UC na realização de atividades de EA.

\section{RESULTADOS E DISCUSSÃO}

\section{I Resultados Da PESQUisa QUALI-QUANTITATIVA}

Os resultados aqui apresentados estão estruturados e organizados de acordo com os questionamentos realizados no questionário enviado aos participantes da pesquisa.

\section{I.I INFORMAÇÕES SOBRE A INFRAESTRUTURA DA UC}

Este item apresenta os resultados obtidos a partir das respostas para as perguntas A1, A2 e A3 do questionário.

\section{A.1- Possui uma sede?}

Todas as unidades de conservação avaliadas informaram possuir uma sede.

A.2- Há espaço para visitação elou atividades internas (ex. sala de aula, museu, herbário, etc...)?

Apenas uma UC, a APA Banhado Grande, informou ainda não existir um local para esta função. Foi informado que a sede está aguardando uma possível reforma para o local. Além disso, foi informado que uma parte pequena da área (apenas 1 ha) é de domínio público, o restante é de domínio privado, excluindo área que é de proteção integral relativa ao Refúgio de Vida Silvestre Banhado dos Pachecos. As outras UCs pesquisadas informaram possuir um local para visitação ou a prática de atividades, como, centro de visitantes, auditório, sala de educação ambiental, exposição fotográfica e/ou um minimuseu.

\section{A.3 - Quantos funcionários trabalham na UC?}

Em relação ao número de funcionários existentes nas UCs pesquisadas, o número variou de 5 à 18 funcionários (do órgão público) por unidade. O Quadro 1 apresenta o detalhamento desta informação para cada UC. 
Quadro 1 - Detalhamento do número de funcionários por UC.

\begin{tabular}{|c|c|}
\hline UC & $\mathrm{N}^{\circ}$ de funcionários \\
\hline $\begin{array}{l}\text { PARNA Aparados da Serra e o } \\
\text { PARNA da Serra Geral }\end{array}$ & Total 18: 8 analistas ambientais, 1 técnico ambiental, 9 servidores terceirizados \\
\hline $\begin{array}{l}\text { PE do Delta do Jacuí e a APA } \\
\text { Delta do Jacuí }\end{array}$ & Total 11: 1 gestor, 8 guardas-parque, 1 auxiliar de serviços rurais e 1 quadro especial. \\
\hline PE de Itapeva & Total 12: 2 técnicos ambientais (biólogos), 4 guardas-parque e 6 agentes administrativos \\
\hline PE de Itapuã & $\begin{array}{c}\text { Total 12: } 8 \text { guardas-parque; } 2 \text { escriturários; } 1 \text { técnica e } 1 \text { agente de serviços rurais (além desses, } 38 \text { vigilantes } \\
\text { patrimoniais terceirizados e eventualmente estagiários). }\end{array}$ \\
\hline APA Banhado Grande & $\begin{array}{l}\text { Total 5: } 1 \text { agente administrativo, } 1 \text { gestora da UC (divide responsabilidade com gestáo de outra UC - APA } \\
\text { Rota do Sol), } 2 \text { técnicas ambientais (uma bióloga e uma eng. agrônoma) e } 2 \text { guardas-parques. }\end{array}$ \\
\hline PNM Morro do Osso & $\begin{array}{c}\text { Total de 10: } 1 \text { gestor, } 1 \text { responsável técnico; } 2 \text { guardas-parque; } 5 \text { servidores nas atividades operacionais e um } \\
\text { estagiário. }\end{array}$ \\
\hline
\end{tabular}

Fonte: (Autora, 2017).

\section{I.2 INFORMAÇÕES SOBRE EdUCAÇÃo AMBIENTAL}

Este item apresenta os resultados obtidos a partir das respostas para as perguntas B1 à B13 do questionário.

B.1 - A UC possui Plano de Manejo? e B.2 - Se sim, há a previsão de atividades ou de um programa de educação ambiental?

Todas as UCs pesquisadas possuem plano de manejo, com exceção da APA Banhado Grande que está em fase de elaboração. Todas estas informaram que o plano de manejo prevê a realização de atividades ou de um plano de educação ambiental.

B.3 - Existe alguma atividade de educação ambiental sendo realizada atualmente?; B.4 - Se sim. Que tipo de atividade é realizada?; B.5 - Com que frequência as atividades de educação ambiental são realizadas?; B.6-Qual o público-alvo destas atividades?; e B.7 - Você considera que há efetividade destas atividades na comunidade atingida?

Todas as UCs informaram também que atualmente estão sendo realizadas as atividades, de acordo com o cronograma de cada uma, com exceção da APA Banhado Grande. Esta informou que não há atividades de educação ambiental sendo realizadas internamente pela gestão da UC, mas sim através de iniciativas de ONGs, que acabam realizando atividades sem vínculo direto com a administração da UC. O Quadro 2 apresenta as informaçóes sobre as atividades de EA das UCs pesquisadas, conforme os questionamentos supracitados.

B.8 - Quais seriam os indicadores para medir a efetividade?

Em relação ao questionamento sobre a efetividade das atividades de EA realizadas, a maioria das UCs respondeu positivamente, sendo os indicadores desta efetividade descritos abaixo:

O PARNA Aparados da Serra e o PARNA da Serra Geral informou que o indicador utilizado é o número de pessoas atingidas pelas atividades, feedbacks recebidos, número de demandas atendidas (principalmente em relação às solicitaçóes de escolas).

O PE do Delta do Jacuí e a APA Delta do Jacuí informou que os indicadores utilizados são os apresentados para o Projeto Guarda-Parque Mirim, o qual inclui depoimentos de alunos, professores, participantes do projeto, além do número de pessoas atingidas.

O PE de Itapeva informou que os indicadores são os feedbacks recebidos através de avaliaçôes após cada atividade e análise posterior por parte da gestão da UC.

$\mathrm{O} \mathrm{PE}$ de Itapuã informou que os indicadores são o retorno da população e das escolas ao Parque, para a realização de mais atividades e trilhas.

A APA do Banhado Grande não possui quantificação ou indicadores, uma vez que não há atividades vinculadas à UC sendo realizadas no momento.

O PNM Morro do Osso informou que os indicadores utilizados são através da postura mais comprometida dos alunos que frequentam à UC, levados por professores que frequentam as oficinas, demonstrando que a visita não é simplesmente um passeio. em geral?

B.9 - Há disponibilização de algum material educativo elou informativo sobre a UC para a comunidade

Apenas duas unidades de conservação informaram não possuir material informativo para os visitantes. As outras UCs informaram que possuem folders, panfletos, banners e/ou página no Facebook. 
Quadro 2 - Resumo das informaçóes sobre as atividades de EA nas UCs pesquisadas.

\begin{tabular}{|c|c|c|c|c|c|}
\hline UC & $\begin{array}{c}\text { Tipo de Atividade e/ou } \\
\text { Programa }\end{array}$ & Frequência & Público-alvo & Há efetividade & $\begin{array}{c}\text { Material } \\
\text { educativo/ } \\
\text { informativo }\end{array}$ \\
\hline $\begin{array}{l}\text { PARNA } \\
\text { Aparados } \\
\text { da Serra e o } \\
\text { PARNA da } \\
\text { Serra Geral }\end{array}$ & $\begin{array}{l}\text { Programa de educaçáo } \\
\text { ambiental com atividades } \\
\text { de diversas naturezas } \\
\text { programadas de acordo } \\
\text { com o público alvo a serem } \\
\text { executadas em períodos } \\
\text { diferentes do ano }\end{array}$ & $\begin{array}{l}\text { Cada atividade tem } \\
\text { seu cronograma }\end{array}$ & $\begin{array}{l}\text { Crianças e adolescentes, } \\
\text { principalmente em idade } \\
\text { escolar, público visitante das } \\
\text { UCs e moradores do entorno }\end{array}$ & $\operatorname{sim}$ & nâo \\
\hline $\begin{array}{l}\text { PE do Delta } \\
\text { do Jacuí e a } \\
\text { APA Delta } \\
\text { do Jacuí }\end{array}$ & $\begin{array}{l}\text { Projeto Guarda Parque } \\
\text { Mirim é realizado com } \\
\text { escolas públicas situadas no } \\
\text { entorno da UC }\end{array}$ & $\begin{array}{c}\text { Anualmente, } \\
\text { geralmente de julho } \\
\text { a agosto }\end{array}$ & $\begin{array}{l}\text { Alunos dos } 4^{\circ} \text { e } 5^{\circ} \text { anos das } \\
\text { escolas públicas do entorno da } \\
\text { Unidade de Conservaçáo }\end{array}$ & $\operatorname{sim}$ & sim \\
\hline PE de Itapeva & $\begin{array}{c}\text { Projeto Parque Estadual de } \\
\text { Itapeva, conhecer para Amar } \\
\text { e Preservar e Projeto Verão } \\
\text { PEVA }\end{array}$ & $\begin{array}{l}\text { Fora da temporada } \\
\text { de verăo, } \\
\text { semanalmente, e } \\
\text { na temporada de } \\
\text { verāo, diariamente, } \\
\text { podendo ter maior } \\
\text { frequência por } \\
\text { demanda }\end{array}$ & $\begin{array}{l}\text { Principalmente alunos de } \\
\text { escolas da rede pública e } \\
\text { privada, além de universidades. } \\
\text { Na temporada de Verão, } \\
\text { público geral (turistas e } \\
\text { veranistas e demais visitantes) }\end{array}$ & $\operatorname{sim}$ & sim \\
\hline PE de Itapuã & $\begin{array}{l}\text { Palestras, vídeos e trilhas } \\
\text { guiadas com escolas, } \\
\text { faculdades ou grupos de } \\
\text { outras instituiçóes }\end{array}$ & $\begin{array}{l}\text { Semanalmente, } \\
\text { conforme a demanda }\end{array}$ & $\begin{array}{c}\text { Alunos de escolas públicas e } \\
\text { privadas, instituiçôes de ensino } \\
\text { superior e o público visitante } \\
\text { do parque }\end{array}$ & $\operatorname{sim}$ & sim \\
\hline $\begin{array}{c}\text { APA } \\
\text { Banhado } \\
\text { Grande }\end{array}$ & $\begin{array}{c}\text { Não há atividades } \\
\text { vinculadas à gestáo da UC } \\
\text { sendo realizadas }\end{array}$ & - & - & - & - \\
\hline $\begin{array}{l}\text { PNM Morro } \\
\text { do Osso }\end{array}$ & $\begin{array}{l}\text { Oficina de Educação } \\
\text { Ambiental de formaçáo para } \\
\text { professores, acadêmicos da } \\
\text { área ambiental, técnicos em } \\
\text { meio ambiente e para área } \\
\text { de turismo }\end{array}$ & $\begin{array}{l}\text { Semanalmente ( } 3 \\
\text { vezes por semana) }\end{array}$ & $\begin{array}{c}\text { Escolares do ensino } \\
\text { fundamental ao médio, } \\
\text { universitários da área ambiental } \\
\text { e a população em geral }\end{array}$ & $\operatorname{sim}$ & sim \\
\hline
\end{tabular}

B.10 - Qual o público-alvo que você considera o mais importante para a realização das atividades hoje? Por quê?

Sobre o público-alvo considerado o mais importante para a realização de atividades de EA, o Gráfico 1 mostra a frequência de ocorrência das respostas informadas. $43 \%$ dos entrevistados consideraram todos os públicos como sendo o mais importante para ações de EA.

B.11 - Existe Zona de Amortecimento na UC? Itapuã.

Duas das seis UCs não possuem zona de amortecimento, sendo elas a APA Banhado Grande e o PE de

\section{B.12 - A comunidade do entorno participa efetivamente do Conselho Gestor da UC?}

Quanto ao questionamento relativo à participação da comunidade do entorno no conselho gestor da UC, todas as unidades informaram que a comunidade participa da gestão. O PARNA Aparados da Serra e o PARNA da Serra Geral informou que a comunidade participa, mas não de forma efetiva.

B.13 - Na sua percepção, como você considera a relação da comunidade do entorno com a UC?

Quanto à relação da UC com a comunidade do entorno, pela percepção da gestão, a maioria acredita que a relação é de boa à regular. Três UCs consideram a relação com a comunidade boa, e as outras três UCs consideram esta relação regular. 
Gráfico 1 - Público-alvo considerado o mais importante segundo os entrevistados

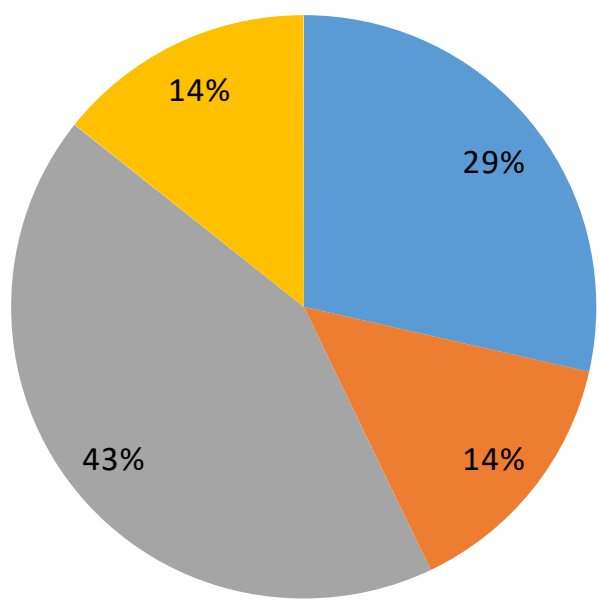

\author{
Alunos Ens. \\ Fundamental (crianças) \\ Aunos Ens. \\ Fundamental e Médio \\ Todos os públicos \\ (estudantes, \\ moradores, produtores \\ rurais, crianças) \\ Professores
}

Fonte: (Autora, 2017).

\title{
3.I.3 Problemas e necessidades
} tionário.

Este item apresenta os resultados obtidos a partir das respostas para as perguntas C1, C2 e C3 do ques-

C.1 - Quais das opçóes abaixo você considera ser o principal problema enfrentado pela UC para a não realização de atividades de educação ambiental?

Os entrevistados foram questionados sobre o que consideravam ser o principal problema enfrentado pela UC para a não realização de atividades de educação ambiental atualmente. Dentre as opções pré-estabelecidas no questionário, foi solicitado que enumerassem de 1 (sendo o maior) a 4 (sendo o menor) os seguintes problemas: falta de incentivo financeiro; falta de pessoal; falta de infraestrutura; falta de especialização e/ou conhecimento na área; e outros. O Gráfico 2 mostra os problemas mais citados com a pontuação "1", ou seja, considerado como o principal problema, sendo que a UC poderia considerar mais de uma das opçôes como sendo "principal problema”.

Gráfico 2 - Problemas mais citados pelos entrevistados

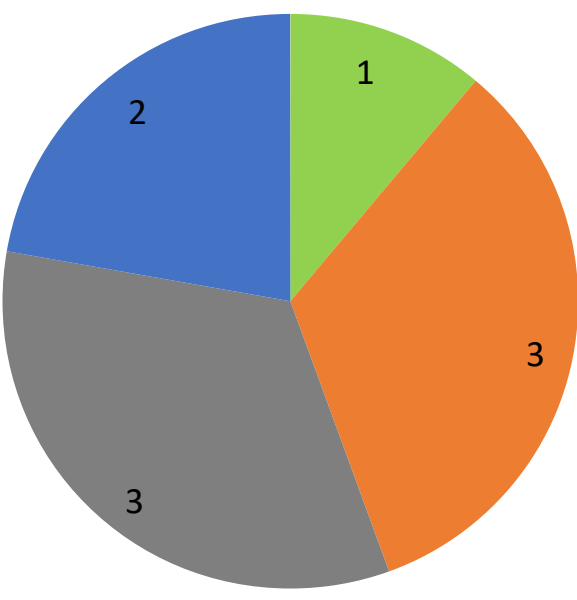

Falta de infraestrutura;

Falta de incentivo

financeiro;

Falta de pessoal;

Falta de especialização

e/ou conhecimento na

área; 
Falta de incentivo financeiro e falta de pessoal foram os problemas que mais obtiveram a pontuação "1", ou seja, foram considerados os principais problemas enfrentados para a não realização das atividades de educação ambiental em três das UCs pesquisadas.

A opção "outros" apareceu como um principal problema em duas UCs. O PE Itapeva informou que falta priorização e sensibilização política dos governantes, assim com falta capacitação no corpo discente (maioria) na Educação Formal da região. A PE e APA Delta do Jacuí também apontaram outros problemas como sendo os principais, não os especificando. E apenas uma UC considerou a falta de infraestrutura como principal problema enfrentado.

C.2 - Na sua percepção, quais as principais necessidades da UC para que haja a realização elou efetividade das atividades de educação ambiental?

Quando questionados sobre quais eram as necessidades da UC para que houvesse a efetividade das atividades de EA, foram citadas as seguintes: recursos humanos, capacitaçáo de pessoal e recursos financeiros para executar as demandas. criaçâo?

C.3 - Na sua percepção, quais as principais necessidades da UC para que haja o alcance dos objetivos de sua

Quando questionados sobre quais eram as necessidades para que houvesse o alcance dos objetivos da criação da UC, foram citadas as seguintes: plano de manejo (e revisão do mesmo), recursos humanos, recursos financeiros, fiscalização, educação ambiental e capacitaçáo de pessoal.

\section{I.4 CONSIDERAÇÕES SOBRE A PESQUISA QUALI-QUANTITATIVA}

De maneira geral, os resultados desta pesquisa são os esperados dentro do contexto evidenciado hoje referente à gestão pública, muitas vezes precária de investimentos em diversos setores.

Quase todas as UCs pesquisadas conseguem, dentro de suas possibilidades, realizar as atividades de EA, com exceção da APA Banhado Grande. Esta UC apresentou situação mais precária em relação a recursos humanos e infraestrutura, não realizando atividades de EA vinculadas diretamente à gestáo da UC.

O público-alvo das ações de EA, apesar de neste estudo ser bastante direcionado para a comunidade escolar, a maioria dos entrevistados (43\%) considerou que o público em geral (moradores, produtores rurais, estudantes, crianças, professores) é considerado como sendo o público mais importante dentro da questáo de unidades de conservação. Valenti et al. (2012) verificaram que a principal atividade de EA realizada pelas UCs pesquisadas são nas escolas, apesar de considerar que a EA inserida no currículo escolar não é uma responsabilidade da UC.

Em relação à efetividade das atividades de EA realizadas, as UCs avaliaram de forma positiva, e conseguem analisar através de indicadores, como número de pessoas atingidas, depoimentos, feedbacks e comportamento de alunos.

A utilização de mecanismos de acompanhamento que possam indicar a efetividade das atividades, apesar de não ter sido levantado detalhadamente neste estudo, é imprescindível para a gestão de uma UC. Num estudo realizado por Valenti et al. (2012) foi verificado que quase 70\% das UCs amostradas no estudo náo utilizam mecanismos nenhum de acompanhamento ou avaliação de suas atividades. Para estes autores, essa é uma questão que merece especial atenção, e consequentemente deve ser incorporada nas discussóes teóricas sobre o assunto.

O plano de manejo é um instrumento importantíssimo, junto com o conselho gestor, para o planejamento e a gestão de uma UC (MINISTÉRIO DO MEIO AMBIENTE, 2010). De qualquer forma, mesmo possuindo o plano de manejo, muitos problemas são enfrentados pelas UCs para a efetivação das açóes de EA e para o alcance dos objetivos da criação da unidade. Problemas como recursos humanos e financeiros, capacitação de pessoal, plano de manejo (e revisão do mesmo) e fiscalização, foram alguns dos fatores citados. Para o WWF (2012), além destes problemas citados, o planejamento adequado e a disponibilidade de recursos são essenciais para que os objetivos de uma UC sejam alcançados.

Nas UCs pesquisadas ocorre a participação da comunidade do entorno no conselho gestor, com exceção da PARNA Aparados da Serra e Serra Geral que informou que participa, mas não efetivamente. Conforme dito anteriormente, o conselho gestor é um dos pilares para o planejamento da gestão de uma UC (MINISTÉRIO DO MEIO AMBIENTE, 2010). E é imprescindível que haja representantes das diferentes comunidades existentes nas UCs no conselho gestor, sendo isto previsto em lei através do Decreto no 4340 de 2002.

Assim, é de extrema importância a participação da comunidade do entorno, fazendo parte de maneira efetiva nos conselhos, para que suas necessidades e anseios sejam ouvidos, e suas opiniōes sejam incluídas nas decisóes da UC, diminuindo assim os potenciais conflitos entre unidade de conservação e comunidades locais.

Neste contexto, a educação ambiental e a comunicação social são ferramentas essenciais para o aprimoramento da gestão e da política da UC, promovendo o acesso a informações e a construção de conhecimentos, assim 
qualificando a participação social na gestáo de áreas protegidas (MINISTÉRIO DO MEIO AMBIENTE, 2015b).

\subsection{PRoposiçÃo de Ações}

Diversas açốes podem ser realizadas com foco nos diferentes grupos sociais e com diferentes objetivos a serem alcançados. Ações podem ser direcionadas para moradores e/ou produtores rurais da UC, comunidade escolar (professores e alunos) de dentro ou do entorno das UCs, conselho gestor da UC, funcionários da prefeitura dos municípios abrangidos, comitês de bacias hidrográficas, e etc...

Para criar um programa ou ações de educação ambiental em uma UC, é importante fazer um diagnóstico prévio da situação, com foco no que se deseja alcançar, para posteriormente implantá-lo. Algumas perguntas iniciais são sugeridas, como:

Qual o problema a ser enfrentado?; Qual o objetivo da açâa?; Qual o público-alvo para alcançar este objetivo? Há recursos humano, financeiro e de infraestrutura para executar esta ação?; De que forma podemos adquirir estes recursos?; Quais seriam os indicadores de efetividade das açôes?

Lembrando que é muito importante levar em consideração que as realidades locais de cada unidade de conservação podem ser bem diferentes, e assim, estratégias distintas podem ser necessárias para alcançar os objetivos propostos.

Uma estratégia sugerida pelo Ministério do Meio Ambiente (2016) para uma investigação inicial é o Diagnóstico Rápido Participativo (DRP), que consiste num "[...] conjunto de ferramentas práticas e ágeis que contribuem no levantamento de informaçôes úteis que servem, sobretudo, para prestar apoio a investigação, planejamento, diagnósticos mais descentralizados e uma tomada de decisão mais democrática que podem subsidiar açôes ou políticas de desenvolvimento" (MINISTÉRIO DO MEIO AMBIENTE, 2016, p.41).

Esta metodologia pode ser utilizada com representantes dos principais grupos sociais envolvidos com a UC. Um exemplo de um DRP em uma UC foi realizado na Unidade de Conservação Marinha, denominada de APARC - Área de Preservação dos Recifes de Corais, onde foi realizado através de questionários e dinâmicas de grupo com os diferentes atores sociais referente às questões socioambientais. Nesse diagnóstico se concluiu que esta metodologia, como uma ferramenta da educação ambiental, pode servir como um sinalizador para os gestores no desenvolvimento de açôes que auxiliem a inclusão social das comunidades nas decisóes das questóes de conservação e desenvolvimento socioambiental sustentável (OLIVEIRA et al., 2010).

A partir desta análise exploratória através do DRP pode-se definir qual o principal problema a ser enfrentado, qual o objetivo da ação a ser realizada, qual o público-alvo da ação e qual ação a ser realizada. Após estes questionamentos respondidos, é preciso avaliar os recursos e potencias parceiros que podem participar e contribuir com esta ação, uma vez que, conforme análise deste estudo, através da opinião dos entrevistados, percebeu-se que ainda há escassez de recursos na maioria das UCs.

O ICMBio lançou a Estratégia Nacional de Comunicação e Educação Ambiental (ENCEA), onde constam diretrizes e propostas de açôes necessárias para o desenvolvimento e aprimoramento de programas de comunicação e educação ambiental. Dentre as diretrizes, podemos listar resumidamente algumas que sugerem parcerias e articulação com outras instituiçóes:

Aproximar a gestão da UC de processos como Comitês de Bacias Hidrográficas, Conselhos Municipais de Meio Ambiente, Planos Diretores e outras formas de organização sócia;

Potencializar pesquisas em comunicação e educação ambiental na UC através de linhas de pesquisas e extensão, com participação de pesquisadores nos programas de EA das UC e da concessão de bolsas e parcerias entre diversas instituiçóes;

Incentivar a realização de projetos de iniciação científica, programas de estágio e pesquisas acadêmicas no interior e entorno de UC através de parcerias com universidades e com instituições de fomento à pesquisa;

Desenvolver e implantar metodologias que utilizem as unidades de conservação como cenário para o ensino e a pesquisa, bem como espaço para a adoção de práticas sustentáveis através da articulação com as secretarias de educação e demais instituiçôes de ensino;

Oportunizar formação continuada das equipes das UC e parceiros, incentivando a troca de experiências sobre Educação Ambiental e Comunicação a partir da realização de encontros, cursos, seminários, oficinas, reuniōes, intercâmbios e eventos diversos.

Além disso, foi lançado em 2015, cinco cadernos da série "Educação Ambiental e Comunicação em Unidades de Conservação", onde constam muitas informaçôes norteadoras para a gestáo ambiental em UCs, disponíveis para download no site do Ministério do Meio Ambiente.

Neste contexto, o Caderno 5 traz outras sugestôes para captação de recursos para gestão das UCs (MINISTÉRIO DO MEIO AMBIENTE, 2015c), entre estas: 
ICMS Ecológico: possibilita aos municípios parcelas maiores da arrecadação do ICMS para aqueles que atendem critérios ambientais, como criação e preservação de áreas protegidas;

Compensação Ambiental: empreendimentos de significativo impacto ambiental devem aportar recursos implementação e manutenção de UCs de Proteção Integral.

Este mesmo caderno também traz a sugestão de formação de servidores e de outros atores sociais na área de educação ambiental, tanto no âmbito do ICMBio quanto no âmbito do Sisnama, onde são oferecidos cursos em três linhas temáticas: curso de Gestão Socioambiental, curso de Gestão de Conflitos e, para a formação de educadores ambientais, curso de Educação Ambiental na Gestão da Biodiversidade. A formação e capacitação de educadores ambientais é muito importante para a eficácia de açóes de educação ambiental, uma vez que muitas vezes a abordagem utilizada com os diferentes atores sociais pode (e deveria) desenvolver comportamentos socioambientais corretos, e ao mesmo tempo, serem multiplicados e reproduzidos nas comunidades.

Outra questão muito importante nas açóes de EA é o acompanhamento e o monitoramento das atividades através de indicadores e critérios de avaliação. Para o Ministério do Meio Ambiente (2015 c), os objetivos dos processos de avaliação envolvem três açôes: medir continuamente, comparar o obtido com o previsto e tomar decisões. O planejamento das ações envolve o monitoramento e a avaliação, os quais devem disponibilizar elementos afim de definir estratégias mais apropriadas para cada ocasião (MINISTÉRIO DO MEIO AMBIENTE, 2015c). O Caderno 1 e o Caderno 5 do Ministério do Meio Ambiente trazem exemplos de indicadores socioambientais, assim como, métodos e parâmetros de avaliação.

Por fim, estas publicaçóes do Ministério do Meio Ambiente também trazem experiências de sucesso de açóes de EA em Unidades de Conservação Federais. Por exemplo, o Caderno 1 traz uma experiência na APA Nascentes do Rio Vermelho, onde houve o fortalecimento da agricultura familiar local, e outra experiência foi na FLONA de Tefé, na RESEX do rio Jutaí e na RESEX do Baixo Juruá, onde ocorreu articulação entre estas UCs para a implantação de um projeto em comum. Outro documento que traz registro de experiências é o intitulado "Registro de Experiências de Educação Ambiental e Comunicação desenvolvidas em Unidades de Conservação Federias" elaborado em 2015 pelo Ministério do Meio Ambiente e o ICMBio por intermédio da Solar Consultoria, onde foram registradas 73 experiências de EA em 50 UCs.

\section{CONCLUSÕES}

A realização e efetividade das atividades de educação ambiental demandam recursos humanos, financeiros e de infraestrutura. Conforme verificado neste estudo e em outras pesquisas, muitas unidades de conservaçáo não possuem recursos suficientes para realizar, acompanhar, monitorar as atividades de EA de forma efetiva.

Através da pesquisa realizada e da bibliografia consultada (MINISTÉRIO DO MEIO AMBIENTE, 2010) foi possível perceber que os pilares da gestão ambiental em UC são o plano de manejo efetivo e o conselho gestor atuante na tomada de decisões.

A Educação Ambiental é fundamental para que estes pilares atuem de forma efetiva (LOUREIRO e CUNHA, 2008; MINISTÉRIO DO MEIO AMBIENTE, 2016). A gestão participativa em UCs é muito importante para reduzir conflitos existentes entre comunidades e áreas protegidas.

Articulação e parcerias com instituiçóes educacionais e de pesquisa, com secretarias de meio ambiente e de educação dos municípios, com ONGs, com comitês de bacias hidrográficas, com organizaçóes de fomento, e com a própria comunidade local, parecem ser uma importante estratégia para driblar a falta de recursos humanos, financeiros e de infraestrutura das UCs.

A pesquisa e consulta a casos de sucesso de atividades de educação ambiental em unidades de conservação também pode ser uma ferramenta importante para elucidar questionamentos, nortear e planejar ações e delinear estratégias.

\section{AGRADECIMENTOS}

Agradecemos primeiramente à Universidade Federal de Santa Maria, através do Programa Universidade Aberta do Brasil, por possibilitar a realização da Especialização em Educação Ambiental que, consequentemente, gerou este estudo. E agradecemos aos gestores, funcionários, estagiários das Unidades de Conservação por dispensarem alguns minutos de seu tempo para participarem desta pesquisa. 


\section{REFERÊNCIAS}

BROCKELMAN,W. Y.; GRIFFITHS, M. Mecanismos de fortalecimento das áreas protegidas. In: Tornando os parques eficientes: estratégias para conservação da natureza nos trópicos. Curitiba: Universidade Federal do Paraná, 2002. p. 290-304.

FERREIRA, L. V.; VENTICINQUE, E.; ALMEIDA, S. O desmatamento na Amazônia e a importância das áreas protegidas. Estudos Avançados. Sáo Paulo, v. 19 (53), p.157-166. 2005. DOI: 10.1590/S0103-40142005000100010.

GROSS, T.; JOHNSTON, S.; BARBER, C. V. A Convençáo sobre Diversidade Biológica: Entendendo e influenciando o Processo. Instituto de Estudos Avançados das Naçôes Unidas. 2006.

HESSLER, M. L. A importância das unidades de conservação no Brasil. Sociedade e Natureza. Uberlândia, v. 17 (33), p. 79-89. 2005.

LIMA, G. S.; RIBEIRO, G. A.; GONÇALVES, W. Avaliaçấo da efetividade de manejo das Unidades de Conservação de proteção integral em Minas Gerais. R. Árvore. Viçosa, v.29, n.4, p.647-653. 2005. DOI: 10.1590/S010067622005000400017.

LOUREIRO, C. F; CUNHA, C. C. Educação ambiental e gestão participativa em unidades de conservaçấo: elementos para se pensar a sustentabilidade democrática. Ambiente \& Sociedade. Campinas, v. 11, n. 2. P. 237:253. jul- -dez, 2008.

WWF. Efetividade da gestáo das unidades de conservaçáo federais do Brasil: resultados de 2010. 2012. Disponível em: https://www.wwf.org.br/informacoes/bliblioteca/?31645/Efetividade-de-Gesto-das-Unidades-de-Conservao-Federais-do-Brasil-resultados-de-2010. Acesso em 20 set. 2017.

MINISTÉRIO DO MEIO AMBIENTE. A unidade de conservaçáo e o território: Reconhecendo o contexto socioambiental e geopolítico. Série Educação Ambiental e Comunicação em Unidades de Conservação. Caderno 1. 2015 a. Disponível em: http://www.mma.gov.br/publicacoes/educacao-ambiental/category/154-serie-ea-uc. Acesso em: 15 set. 2017.

MINISTÉRIO DO MEIO AMBIENTE. Conflitos: estratégias de enfrentamento e mediação. Série Educação Ambiental e Comunicação em Unidades de Conservação. Caderno 4. 2015 b. Disponível em: http://www.mma.gov.br/ publicacoes/educacao-ambiental/category/154-serie-ea-uc. Acesso em: 15 set. 2017.

MINISTÉRIO DO MEIO AMBIENTE. Tornar-se visível: estratégia para promover articulaçóes e captar recursos. Série Educação Ambiental e Comunicação em Unidades de Conservação. Caderno 5. 2015 c. Disponível em: http:// www.mma.gov.br/publicacoes/educacao-ambiental/category/154-serie-ea-uc. Acesso em: 15 set. 2017.

MINISTÉRIO DO MEIO AMBIENTE. Educaçáo ambiental em unidades de conservaçáo: 2016 açóes voltadas para comunidades escolares no contexto da gestáo pública da biodiversidade. 2016. Disponível em: http://www. icmbio.gov.br/portal/images/stories/comunicacao/publicacoes/publicacoes-diversas/DCOM_ICMBio_educacao_ ambiental_em_unidades_de_conservacao.pdf. Acesso em: 25 jul. 2017.

D’OLIVEIRA, R. G. et al. Diagnóstico rápido participativo - uma ferramenta de educaçáo ambiental. Anais/Resumos da 62a Reunião Anual da SBPC - SSN 2176-1221. 2010. Disponível em: www.sbpcnet.org.br/livro/62ra/resumos/ resumos/4559.htm. Acesso em: 05 out. 2017.

QUINTAS, J. S. Por uma educação ambiental emancipatória: consideraçóes sobre a formação do educador para atuar no processo de gestão ambiental. In: QUINTAS, J. S. (Org.). Pensando e praticando a educaçáo ambiental na gestão do meio ambiente. Brasília: IBAMA. (3 ed.) p. 11-19. 2006. ISBN 85-7300-235-2.

VALENTI, M. W. et al. Educação Ambiental em Unidades de Conservaçáo: Políticas Públicas e a Prática Educativa. Educaçáo em Revista. Belo Horizonte, v.28, n.01, p.267-288. 2012. DOI: 10.1590/S0102-46982012000100012. 
ZAPPES, C.A. Estudo Etnobiológico comparativo do conhecimento popular de pescadores em diferentes regióes do litoral brasileiro e implicaçóes para a conservaçáo do Boto-cinza Sotalia guianensis (van Bénéden, 1864) (Cetacea, Delphinidae). 2007. 161p. Dissertação (Mestrado em Ciências Biológicas Comportamento e Biologia Animal) - Universidade Federal de Juiz de Fora. Juiz de Fora. 2007. 